\title{
THE INFLUENCE OF THERMOMECHANICAL COUPLING ON THE BEHAVIOUR OF ATHICK-WALLED METALLIC TUBE SUBJECTED TO INTERNAL PRESSURE
}

\author{
Z. ŚLODERBACH \\ Opole University of Technology \\ Institute of the Innovation of Processes and Products \\ Faculty of Managing the Power Industry \\ 45-370 Opole, ul. Ozimska 75, POLAND \\ E-mail: z.sloderbach@po.opole.pl
}

\begin{abstract}
In this study, the influence of thermomechanical coupling effect - the effect of thermal expansion due to dissipation of the energy of plastic deformation, with and without taking into account the stored energy of plastic deformation (SEPD) for the distribution of stresses, strains, temperature, the applied pressure and the residual stresses is examined. The residual stresses remain in a thick-walled tube (a cylindrical thick-walled tank) after removing the internal pressure in the process of purely elastic unloading. The analysis is made on the example of an analitycal solution for a thick-walled tube subjected to a quasistatically increasing internal pressure for the case of adiabatic processes (without heat flow). Since the loading with internal pressure is quasi-static (monotonic), then neglecting the process of heat flow can lead to some different results in calculated stresses, deformations, temperature, internal pressure and residual stresses. The calculations for isothermal type of processes of deformations (without heat or ideal cooling) are also performed for the estimation of these differences. The results calculated for the process with heat flow should be intermediate between the values obtained for isothermal and adiabatic processes.
\end{abstract}

Key words: thick-walled tube, thermomechanical coupling, actual and residual stresses, strain, pressure.

\section{Introduction}

The analysis was performed on the example of an analytical solution for a thick-walled tube (a cylindrical thick-walled tank) loaded by quasi-statically increasing internal pressure for the case of a locally adiabatic process (without heat flow). For the case of a locally adiabatic process the obtained results of internal pressure should be smaller in comparison with the solutions obtained in the case of the process with heat flow. For the case of isothermal processes (ideal cooling), the results should be in the upper limit of the solution obtained in the case of heat flow processes. These two estimations do not differ significantly. The precise calculations, taking into consideration heat flow are very complicated (and most of them have to be solved by numerical methods) and sometimes this type of solutions are not necessary from the practical point if view.

The constitutive equations of elastic-plastic material with linear hardening without taking into account the influence of temperature on plastic yield stress and the coefficient of linear hardening were applied, since the maximum temperature increases are of the order of $40 \mathrm{~K}$. Results presented in, e.g. (Bland, [1]; Koiter, [2]; Mendelson, [3]; Nied and Batterman, [4]; Sokołowski, [5]; Śloderbach et al., [6], [7]; Życzkowski and Kordas [8]) were used in the derivation of basic relations for the case of a thick-walled tube and thick-walled hollow sphere and their solution. However, in comparison with the important work (Nied and Batterman, [4]), we take additionally into consideration the efect of the stored energy of plastic 
deformation (SEPD), see e.g. (Bever et al., [9]; Śloderbach et al., [10], Śloderbach and Pajak, [11]) on the process of adiabatic thermo-elastic-plastic deformation.

In order to simplify the calculations, it is assumed that all the material constants of a thermo-elasticplastic body model are independent of temperature. This simplification can be justified by a relatively small rise of temperature (tens degrees Kelvin), caused by energy dissipation of plastic deformation. It seems worth noting that for soft steel, for example, the changes of Young's modulus and yield stress are of the order $\sim 16 \%$ for temperatures of about $700 \mathrm{~K}$ (Sawczuk et al., [12]). In the analysis of the problem of thermomechanical coupling the theory of thermo-plastic small deformations is used, which is considered to be correct for a relatively large load range.

In some technological and engineering problems sometimes we have situations in which the velocity of propagation of plastic deformations $\left(\dot{\varepsilon}^{p}>10^{-1} s^{-1}\right)$ is comparable with the velocity of propagation of the heat flow. In such cases the solution for locally adiabatic process is the same as the solution obtained for the case taking into account the heat flow process (in our case through the wall of a thick-walled tube). The results of calculations are presented in the form of appropriate diagrams and in the table.

\section{The solution for a thick-walled tube}

\subsection{Introduction}

Let us consider the thick tube made of metal, hollow inside and loaded with monotonically (quasistatically) increasing internal pressure. This pressure increases until a half of the tube wall becomes plastic, see Fig.1.

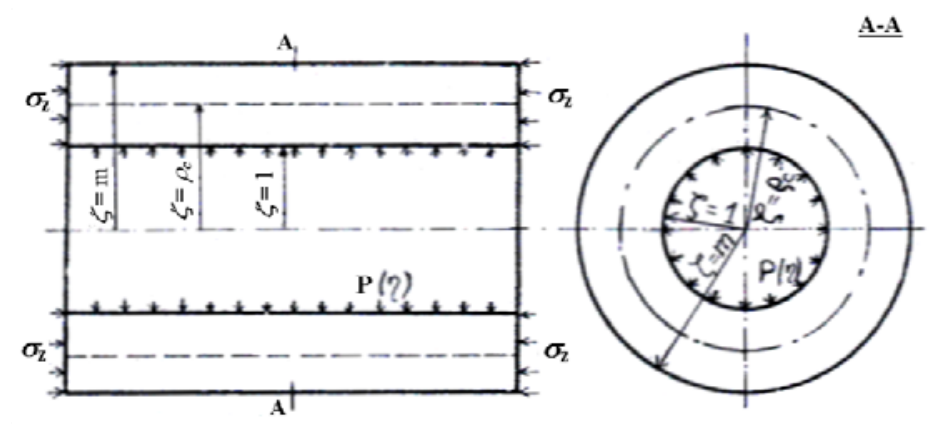

Fig.1. The thick-walled tube, loaded with monotonically (quasistatically) increasing internal pressure $p$ which is in plane states of deformations (PSD).

We assume that the thick-walled tube is in a in plane state of strains.

The material of the tube is assumed to be elastic-plastic with isotropic hardening satisfying the Tresca condition of plasticity and its associated flow rule.

For solutions the cylindrical system of coordinates $(r, \theta$ and $z)$ is applied.

The yield strength and the hardening parameter do not depend on the temperature field. Constitutive equations of plastic deformation are incremental equations of the Prandtl-Reuss type (Mendelson, [3]), which in the case of quasistatic loading, by integrating become the equations of deformation type (Koiter, [2]; Mendelson, [3]; Nied and Batterman, [4]; Hill, [13]). In order to solve the problem, the description with the use of cylindrical coordinates is applied. In this paper, in comparison e.g. with papers (Bland, [1]; Koiter, [2]; Mendelson, [3]; Sokołowski, [5]; Życzkowski and Kordas [8]), the distributions of internal pressure, depending on the location of the elastic-plastic zone, and residual stress distributions were determined. In this paper, three problems are examined: thermomechanically coupled with and without (SEPD) and also an uncoupled one. 
Calculations were performed with the use of a computer program. The obtained results of calculations are presented in the form of appropriate diagrams and in the table.

\subsection{Basic initial equations}

The equilibrium equation, the condition of continuity of strain and geometric relations for the case of cylindrical symmetry and for the plane state of deformations have the following formulae (Bland, [1]; Koiter, [2]; Mendelson, [3]; Sokołowski, [5]; Życzkowski and Kordas [8]; Hill, [13])

$$
\begin{aligned}
& \frac{d \sigma_{r}}{d r}+\frac{\sigma_{r}-\sigma_{\theta}}{r}=0, \\
& \frac{d \varepsilon_{\theta}}{d r}+\frac{\varepsilon_{\theta}-\varepsilon_{r}}{r}=0, \\
& \varepsilon_{r}=\frac{d u}{d r}, \quad \varepsilon_{\theta}=\frac{u}{r} \quad \text { and } \quad \varepsilon_{z}=0
\end{aligned}
$$

where: $u$ - the displacement along radius $r$.

The relations between stress and deformation are as follows

$$
\begin{aligned}
& \varepsilon_{r}=\frac{1}{E}\left[\sigma_{r}-v\left(\sigma_{\theta}+\sigma_{z}\right)\right]+\varepsilon_{r}^{p}+\alpha \Delta T, \\
& \varepsilon_{\theta}=\frac{1}{E}\left[\sigma_{\theta}-v\left(\sigma_{r}+\sigma_{z}\right)\right]+\varepsilon_{\theta}^{p}+\alpha \Delta T, \\
& \varepsilon_{z}=\frac{1}{E}\left[\sigma_{z}-v\left(\sigma_{r}+\sigma_{\theta}\right)\right]+\varepsilon_{\theta}^{p}+\alpha \Delta T=0 .
\end{aligned}
$$

The condition of plastic incompressibility is the following

$$
\varepsilon_{r}^{p}+\varepsilon_{\theta}^{p}+\varepsilon_{z}^{p}=0
$$

As we assumed the Tresca yield criterion and its associated flow rule will be used, since in this case it offers some simplifications. For this purpose, it will be assumed that $\left(\sigma_{\theta} \geq \sigma_{z} \geq \sigma_{r}\right)$. It is shown by Koiter [2] that this is true for a large range of conditions.

Stress intensity for the Tresca condition of plasticity is as follows (Mendelson [3])

$$
\sigma_{e}=\sigma_{\theta}-\sigma_{r}
$$

then the condition of initial plastic flow is as follows

$$
\sigma_{e}=\sigma_{0}
$$

From the Tresca yield criterion and its associated flow rule it follows, that 


$$
\varepsilon_{z}^{p}=0
$$

From the condition of plastic incompressibility (2.5) it follows that

$$
\varepsilon_{r}^{p}=-\varepsilon_{\theta}^{p}
$$

For the case of cylindrical symmetry and the condition of plastic incompressibility (2.8) and (2.9), the increment of replacement of plastic deformation is

$$
\varepsilon^{p}=\frac{2}{\sqrt{3}}\left|\varepsilon_{r}^{p}\right|
$$

From expression $(2.4)_{3}$ and after using in Eq.(2.8) we can obtain

$$
\sigma_{z}=v\left(\sigma_{r}+\sigma_{\theta}\right)-E \alpha \Delta T
$$

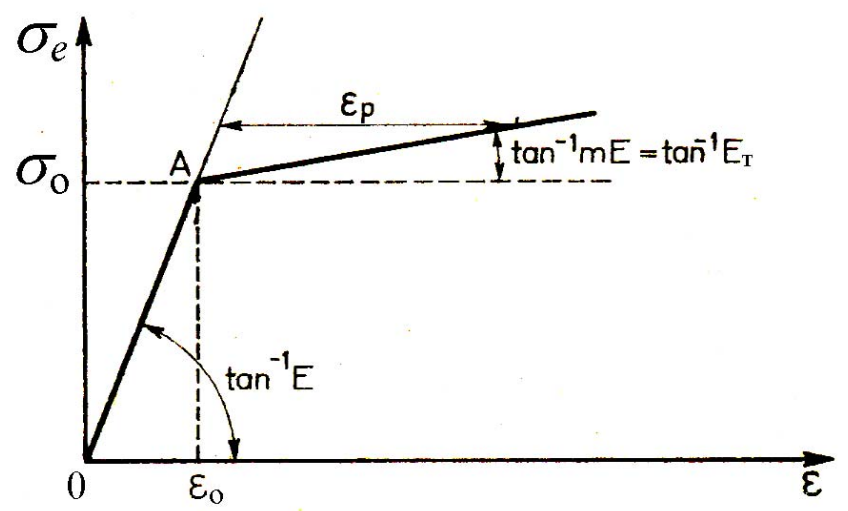

Fig.2. Curve stress-plastic strain for linear hardening.

The constitutive equation for the elastic-plastic material with linear hardening, see Fig.2, can be written in the following form (Mendelson, [3]; Nied and Batterman, [4]; Śloderbach et al., [6], [7])

$$
\sigma_{e}=\sigma_{0}+\frac{E_{T} E}{E-E_{T}} \varepsilon^{p}
$$

\subsection{Derivation of basic relations}

\subsubsection{Plastic zone $-\left(1 \leq \zeta \leq \zeta_{c}\right)$, see Fig.1}

Using Eqs (2.4), (2.8), (2.9) and (2.10) and taking into account the fact that in the case of internal pressure load, the stress $\sigma_{\theta}$ is always positive and the stress $\sigma_{r}$ is always negative (Bland, [1]; Koiter, [2]; Mendelson, [3]), hence: $\sigma_{r}-\sigma_{\theta} \leq 0$. After some transformations we obtain 


$$
\begin{aligned}
& \varepsilon_{r}=\frac{1}{E}\left[\sigma_{r}-v\left(\sigma_{\theta}-\sigma_{z}\right)\right]+\frac{\sqrt{3}}{2}\left(\frac{1}{E_{T}}-\frac{1}{E}\right)\left[\sigma_{0}+\left(\sigma_{r}-\sigma_{\theta}\right)\right]+\alpha \Delta T, \\
& \varepsilon_{\theta}=\frac{1}{E}\left[\sigma_{\theta}-v\left(\sigma_{r}+\sigma_{z}\right)\right]-\frac{\sqrt{3}}{2}\left(\frac{1}{E_{T}}-\frac{1}{E}\right)\left[\sigma_{0}+\left(\sigma_{r}-\sigma_{\theta}\right)\right]+\alpha \Delta T .
\end{aligned}
$$

Since the process of deformation in the plastic zone is adiabatic, then the effects of thermomechanical coupling in the elastic zone can be neglected.

Equations for the temperature field of the adiabatic process and for stored energy of plastic deformation (SEPD) we can write as Śloderbach and Pająk, [7]; Raniecki, [14]; Śloderbach, [15]

and

$$
\rho_{0} c_{\sigma} \dot{T}=\dot{W}^{p}-\rho_{0} \dot{E}_{s}
$$

$$
\rho_{0} E_{s} \cong B_{0}\left(\sigma_{e}^{2}-\sigma_{0}^{2}\right)
$$

where: $\dot{W}^{p}$ - power of plastic deformations, $\dot{E}_{s}$ - power of energy stored.

Expression $(2.14)_{1}$ is obtained from the general equation on the temperature field for the case of the adiabatic process and after neglecting the piezocaloric effect (Śloderbach and Pająk, [7]; Raniecki, [14]; Śloderbach, [15], [16]).

Substituting constitutive Eqs (2.13) into the equation of inseparability of deformation (2.2) and using the equation of equilibrium (2.1) and expressions (2.11), (2.12), (2.13), after transformations we obtain the following differential equation of 2 nd order

$$
r^{2} \frac{\partial^{2} \sigma_{r}}{\partial r^{2}}+3 r \frac{\partial \sigma_{r}}{\partial r}=a-\operatorname{Br} \frac{\partial T}{\partial r}
$$

where

$$
A=\frac{2 \sqrt{3}\left(1-E_{T} / E\right) \sigma_{0}}{2\left(1-v^{2}\right) \frac{E_{T}}{E}+\sqrt{3}\left(1-\frac{E_{T}}{E}\right)},
$$

and

$$
B=\frac{2(1+v) \alpha E_{T}}{2\left(1-v^{2}\right) \frac{E_{T}}{E}+\sqrt{3}\left(1-\frac{E_{T}}{E}\right)} .
$$

Substituting the relationship $(2.14)_{2}$ and (2.8) to Eq.(2.14) $)_{1}$ and also taking into account the properties of axial symmetry, after transformations we obtain the following differential equation of 1 st order

$$
\rho_{0} c_{\sigma} \frac{\partial T}{\partial t}=\left(D-\frac{\sqrt{3}}{2} B_{0}\right) \frac{\partial}{\partial t}\left[r^{2}\left(\frac{\partial \sigma_{r}}{\partial r}\right)^{2}\right]
$$

where

$$
D=\frac{\sqrt{3}}{4}\left(1-\frac{E_{T}}{E}\right) \frac{1}{E_{T}} .
$$


Equations (2.15) and (2.16) are apparently reciprocally coupled thermomechanical equations, which means physically that a stress field depends on the temperature field and the temperature field depends on the stress field. These are two basic equations employed to calculate the stress $\sigma_{r}$ and temperature $T$ field in the plastic zone.

Similarly as in Nied and Batterman, [4]; Śloderbach et al., [6]; Śloderbach and Pająk, [7], let us introduce the following dimensionless quantities

$$
\begin{aligned}
& \sigma=\frac{\sigma_{r}}{\sigma_{0}}, \quad \bar{\sigma}=\frac{\sigma_{\theta}}{\sigma_{0}}, \quad \Theta^{*}=b \frac{\Delta T}{T_{0}}, \quad \eta=\frac{k t}{R_{z}^{2}}, \quad k=\frac{K}{\rho_{0} c_{\sigma}}, \quad p=\frac{P}{\sigma_{0}}, \quad \varepsilon=\frac{\varepsilon_{\rho} E}{\sigma_{0}}, \\
& \bar{\varepsilon}=\frac{\varepsilon_{\phi} E}{\sigma_{0}}, \quad \varsigma=\frac{r}{R_{w}}, \quad \varsigma_{c}=\frac{r_{c}}{R_{w}}, \quad \bar{z}=\frac{R_{z}}{R_{w}}, \quad \frac{d}{d r}=\frac{1}{R_{w}} \frac{d}{d \varsigma}, \quad \frac{d^{2}}{d r^{2}}=\frac{1}{R_{w}^{2}} \frac{d^{2}}{d \varsigma^{2}} . \\
& \hat{\sigma} \equiv \sigma_{3}=\frac{\sigma_{z}}{\sigma_{0}}, \quad \hat{\varepsilon}=\frac{\varepsilon_{z} E}{\sigma_{0}} \quad \text { and } \quad \Theta^{*}=b_{r} \frac{\Delta T}{T_{0}} .
\end{aligned}
$$

After taking into account dimensionless quantities (2.17) in differential Eqs (2.15) and (2.16), these equations take the following form

$$
\begin{aligned}
& \frac{\partial^{2} \sigma}{\partial \varsigma^{2}}+\frac{3}{\varsigma} \frac{\partial \sigma}{\partial \varsigma}=\frac{a}{\varsigma^{2}}-\frac{1}{\varsigma} \frac{\partial \Theta^{*}}{\partial \varsigma} \\
& \frac{\partial \Theta^{*}}{\partial \eta}=(\delta-\gamma) \frac{\partial}{\partial \eta}\left[\varsigma^{2}\left(\frac{\partial \sigma}{\partial \eta}\right)^{2}\right]
\end{aligned}
$$

where: $\quad a=\frac{A}{\sigma_{0}}, \quad b_{r}=B \frac{T_{0}}{\sigma_{0}}$ and

$$
\begin{gathered}
\delta=\frac{\sqrt{3}\left(1-\frac{E_{T}}{E}\right)(1+v)}{2\left[2\left(1-v^{2}\right) \frac{E_{T}}{E}+\sqrt{3}\left(1-\frac{E_{T}}{E}\right)\right] \frac{\alpha \sigma_{0}}{\rho_{0} c_{\sigma}}}=B D \frac{\sigma_{0}}{\rho_{0} c_{\sigma}}, \\
\gamma=\frac{\sqrt{3}(1+v) E_{T}}{2\left(1-v^{2}\right) \frac{E_{T}}{E}+\sqrt{3}\left(1-\frac{E_{T}}{E}\right)} \frac{\alpha \sigma_{0} B_{0}}{\rho_{0} c_{\sigma}}=\frac{\sqrt{3}}{2} B_{0} \frac{\delta}{D} .
\end{gathered}
$$

Parameters $\delta$ and $\gamma$ represents thermochemical coupling related to dissipation of work of plastic deformation and to stored energy of plastic deformation (SEPD). It results from Eq.(2.20.)2, that parameter $\gamma$ is a function of parameter $\delta$, which has a physical explanation. For the majority of metallic materials, the parameter of thermomechanical coupling $\delta$ is of order $10^{-3}$, see Nied and Batterman [4] and parameter $\gamma$ is smaller since it represents the part of work of plastic deformation which is stored in a material. When 
parameter $\delta$ is equal to zero $(\delta=0)$, then the solution to the problem becomes non-coupled and we deal with the non-coupled theory of elastoplasticity.

Proceeding similarly as in papers (Nied and Batterman [4]; Śloderbach and Pająk, [7]) and using the following initial-boundary conditions in differential Eqs (2.18) and (2.19)

$$
\sigma(1, \eta)=-p, \quad \sigma(\bar{z}, \eta)=0, \quad \Delta T(\varsigma, 0)=0,\left.\quad \varsigma_{c} \frac{\partial \sigma(\varsigma)}{\partial \varsigma}\right|_{\varsigma=\varsigma_{c}}=1
$$

and solving the differential Eq.(2.19), we get the equation for the temperature field $\Theta *$ which has the following form

$$
\Theta *(\varsigma, \eta)=(\delta-\gamma)\left[\varsigma^{2}\left(\frac{\partial \sigma}{\partial \varsigma}\right)^{2}-\varsigma_{c}^{2}\left(\left.\frac{\partial \sigma}{\partial \sigma}\right|_{\varsigma=\varsigma_{c}}\right)^{2}\right]
$$

Introducing Eq.(2.19) into Eq.(2.18) after transformation we obtain the following differential equation of the 2 nd order

$$
\varsigma^{2} \frac{\partial^{2} \sigma}{\partial \varsigma^{2}}+3 \varsigma \frac{\partial \sigma}{\partial \varsigma}=a-(\delta-\gamma) \varsigma \frac{\partial}{\partial \varsigma}\left[\varsigma^{2}\left(\frac{\partial \sigma}{\partial \varsigma}\right)^{2}\right] .
$$

Taking into account initial-boundary conditions (2.21) and the fact that on the border of the elasticplastic zone stress, strain, displacement and temperature are continous, respectively, and proceeding similarly as in the Appendix to the paper by Nied and Batterman [4], after tedious transformations we obtain from Eq.(2.23) the following expression

$$
\begin{aligned}
& \sqrt{1+4(\delta-\gamma)\left[-2 \sigma+a \ln \frac{\varsigma}{\varsigma_{c}}+(\delta-\gamma)+\frac{\varsigma_{c}^{2}}{\bar{z}^{2}}\right]}+ \\
& +[1+a(\delta-\gamma)] \ln \left[-1-a(\delta-\gamma)+\sqrt{1+4(\delta-\gamma)\left[a \ln \frac{\varsigma}{\varsigma_{c}}-2 \sigma+(\delta-\gamma)+\frac{\varsigma_{c}^{2}}{\bar{z}^{2}}\right]}=\right. \\
& =-2 \ln \frac{\varsigma}{\varsigma_{c}}+\sqrt{1+4(\delta-\gamma)[1+(\delta-\gamma)]}+ \\
& +[1+a(\delta-\gamma)] \ln [-1-a(\delta-\gamma)+\sqrt{1+4(\delta-\gamma)[1+(\delta-\gamma)]}]
\end{aligned}
$$

Equation (2.24) represents the dependence of radial strain $\sigma$ on radius $\zeta$ in the plastic deformation zone for given quantity $\zeta_{c}$.

The stress $\sigma$ at the border of the elastic-plastic zone for $\zeta_{c}$, see (Bland, [1]; Koiter, [2]; Mendelson, [3]; Nied and Batterman, [4]; Śloderbach and Pajak, [7]) is

$$
\left.\sigma\right|_{\varsigma=\varsigma_{c}}=-\frac{1}{2}\left(1-\frac{\varsigma_{c}^{2}}{\bar{z}^{2}}\right)
$$


To determine the stress for a non-conjugated thermomechanically problem, when $(\delta=0, \gamma=0)$, it is necessary to apply the L'Hospital rule to Eq.(2.24). After appropriate transformations the following expression is obtained

$$
\left.\sigma\right|_{\delta=0}=\frac{a}{2} \ln \frac{\varsigma}{\zeta_{c}}+\frac{1}{2}\left(1-\frac{a}{2}\right)\left(1-\frac{\varsigma_{c}^{2}}{\varsigma^{2}}\right)-\frac{1}{2}\left(1-\frac{\varsigma_{c}^{2}}{\bar{z}^{2}}\right) .
$$

This equation is in agreement with that obtained in papers (Bland, [1]; Koiter, [2]; Mendelson, [3]; Nied and Batterman, [4]), however, it is expressed in another form and with the use of other, independent parameters.

Equations (2.22), (2.24)-(2.26) and basic equations presented in subsection 2.2 form the system of equations which can be used to calculate the searched quantities in the plastic deformation zone. Stress distribution $\sigma$ is determined from expressions (2.24) and (2.26) but stresses $\bar{\sigma}$ and $\sigma_{3}$ are next determined from the equilibrium Eq.(2.1) and expression (2.11) after taking into account the appropriate dimensionless quantities (2.17). Temperature distribution in the plastic zone is determined from Eq.(2.22) and distribution of deformations $(\varepsilon$ and $\bar{\varepsilon})$ is determined from Eq.(2.23) after taking into account dimensionless quantities (2.17). The loaded dimensionless inner pressure, dependent on the elastic-plastic zone $\zeta_{c}$ is determined from Eqs (2.24) and (2.26) for radius $(\zeta=1)$, after taking into consideration the boundary condition $(2.21)_{1}$ and for the assumed geometric sphere parameter $\bar{z}$.

The distribution of residual stresses $\left(\sigma^{\prime}, \bar{\sigma}^{\prime}\right.$ and $\left.\sigma_{3}^{\prime}\right)$ after the process of elastic unloading is calculated from the following equations (Bland, [1]; Koiter, [2]; Mendelson, [3]; Nied and Batterman, [4]; Śloderbach and Pajak, [7]; Sawczuk et al., [12])

where

$$
\sigma^{\prime}=\sigma+\sigma^{\prime \prime}, \quad \bar{\sigma}^{\prime}=\bar{\sigma}+\bar{\sigma}^{\prime \prime}, \quad \sigma_{3}^{\prime}=v\left(\sigma^{\prime}+\bar{\sigma}^{\prime}\right)
$$

$$
\sigma^{\prime \prime}=\left.\frac{\varsigma^{2}-\bar{z}^{2}}{\varsigma^{2}\left(\bar{z}^{2}-1\right)} \sigma\right|_{\varsigma=1}, \quad \bar{\sigma}^{\prime \prime}=\left.\frac{\varsigma^{2}+\bar{z}^{2}}{\varsigma^{2}\left(\bar{z}^{2}-1\right)} \sigma\right|_{\varsigma=1}
$$

The derived equations can also be used to solve the problem of hollow sphere with radius $(\zeta=1)$ located in infinite space. Then $(\bar{z} \rightarrow \infty)$ should be substituted into appropriate equations.

We can obtain the equations for the material without hardening when in corresponding expressions we go to the border of $E_{T}\left(E_{T}=0\right)$ or $\left(m=E_{T} / E=0\right)$.

\subsubsection{Elastic zone $-\left(\zeta_{c} \leq \zeta \leq \bar{z}\right)$, see Fig.1}

In this zone the problem of non-coupled thermoelasticity at constant temperature $\left(\Theta^{*}=\right.$ const) is considered. The equations of this type are in standard textbooks (Mendelson, [3]; Boley and Weiner [17]; Nowacki, [18]) and in papers (Bland, [1]; Koiter, [2]; Mendelson, [3]; Nied and Batterman, [4]; Sokołowski, [5]; Śloderbach and Pajak, [7]).

The equation analogous to (2.18) in the elastic zone has the following form

$$
\frac{\partial^{2} \sigma}{\partial \varsigma^{2}}+\frac{3}{\varsigma} \frac{\partial \sigma}{\partial \xi}=-\frac{\delta^{e}}{\varsigma} \frac{\partial \Theta *}{\partial \varsigma}
$$

where 


$$
\delta^{e}=\frac{2\left(1-v^{2}\right)+\sqrt{3}\left(\frac{E_{T}}{E}-1\right)}{2\left(1-v^{2}\right)} .
$$

Parameter $\delta^{e}$ represents thermochemical coupling related to dissipation of work of elastic deformation in the elastic zone.

If we assume that $\left(\Theta^{*}=\right.$ const $\left.=0\right)$, then from Eq.(2.28) after its integration and taking into account border conditions $(2.21)_{1}$ and $(2.25)$, we have that

$$
\sigma=\frac{1}{2} \frac{\left(\varsigma^{2}-\bar{z}^{2}\right)}{\varsigma^{2} \bar{z}^{2}} \varsigma_{c}^{2} .
$$

The distribution of dimensionless stress $\sigma$ is determined from Eq.(2.29) and equilibrium Eq.(2.1) and stresses ( $\bar{\sigma}$ and $\sigma_{3}$ ) from equilibrium Eqs (2.1) and (2.11) after considering appropriate expresions from Eq.(2.17). From Eqs $(2.4)_{1,2}$ the distribution of deformations $(\varepsilon$ and $\bar{\varepsilon}$ ) can be calculated taking into acoount-that in the elastic zone $\left(\varepsilon_{r}^{p}=\varepsilon_{\theta}^{p}=\varepsilon_{z}^{p}=0\right)$ and that dimensionless temperature increment $(\Theta *=0)$. It is important to remember that at the border of the elastic-plastic zone there is a continuity of stresses, deformations and displacements.

The distribution of residual stresses after the process of pure elastic unloading can be determined from Eqs (2.27) and the stresses $\sigma, \bar{\sigma}$ and $\sigma_{3}$ of the unloading process should be taken from the elastic zone.

\section{Analysis and discussion of results}

The results are obtained on the basis of analitycal forms of basic equations and fundamental relations derivated in section 2. Calculations were performed with the use of a computer program.

Figure 3 presents the results of calculations of radial, circumferential and axial stresses $(\sigma, \bar{\sigma}$ and $\left.\sigma_{3}\right)$ for the thermomechanically coupled problem without taking into account $(\delta=1, \gamma=0)$ and with taking into account $(\delta=1, \gamma=0.15)$ the stored energy of plastic deformation (SEPD) and for the thermomechanically uncoupled $(\delta=0, \gamma=0)$ problem. Calculations were performed for the case when the radius of the elasicplastic zone $\zeta_{c}$ is in half of wall of the thick-walled tube, then $\left(\zeta_{c}=1.5\right)$. The geometrical parameter of the tube is $(\bar{z}=2)$, the hardening linear modulus is $\left(m=E_{T} / E=0.4\right)$ and Poisson's coeficient is $(v=0.3)$.

Figure 4 shows the distributions of dimensionless temperatures in the plastic deformations zone with and without taking into account SEPD.

Distributions of radial and circumferential deformations $(\varepsilon$ and $\bar{\varepsilon})$ in the elastic and plastic zone for the thermomechanically coupled problem with and without taking into account the stored energy of plastic deformations and for the thermomechanically uncoupled problem are accordingly presented in Fig.5.

The changes of the applied internal pressure in dependence on the position of the radius of the elasicplastic zone $\zeta_{c}$ until its maximal value $\left(\zeta_{c}=1.5\right)$ are presented in Fig.6. Figure 7 presents calculated curves of residual stresses after pure elastic unloading for the case of maximal value of internal pressure $p$ for $\left(\zeta_{c}=\right.$ 1.5); see points A, B and C on curves in Fig.6.

The condition of the purely elastic unloading process is the following, see (Mendelson, [3]; Sawczuk et al., [12])

$$
\left|\sigma^{\prime}-\bar{\sigma}^{\prime}\right| \leq|\sigma-\bar{\sigma}|
$$

where $\sigma^{\prime}$ and $\bar{\sigma}^{\prime}$ are the stresses determined by the relations (2.27). 
Assuming after papers Bland, [1]; Koiter, [2]; Mendelson, [3]; Nied and Batterman, [4]; Śloderbach and Pajak, [7]) that during elastic unloading the first new local plastic deformations can occur on the inner surface of the thick-walled tube and using expressions (2.27), the condition (3.1) can be transformed to find the critical internal pressure. After this transformation we obtain the following relations for the critical value of internal pressure $p_{c r}$

$$
p_{c r}=\left.\frac{\bar{z}^{2}-1}{\bar{z}^{2}}(\bar{\sigma}-\sigma)\right|_{\varsigma=1} \geq p
$$

where: $p_{c r}$ - is the maximal value of the internal pressure which can be applied during purely elastic unloading without a new plastic deformation that can locally occur on the inner surface of the thick-walled tube.

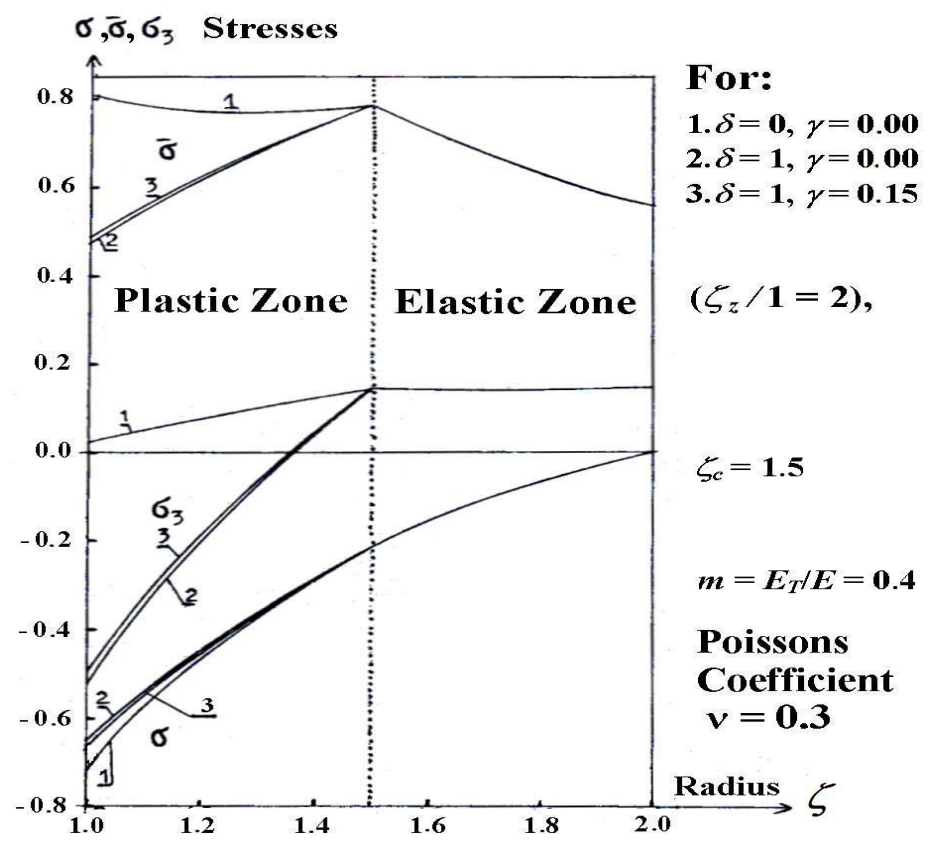

Fig.3. Curves of dimensionless radial $\sigma$, circumferential $\bar{\sigma}$ and axial $\sigma_{3}$ stresses versus current radius of thick-walled tube $\zeta$.

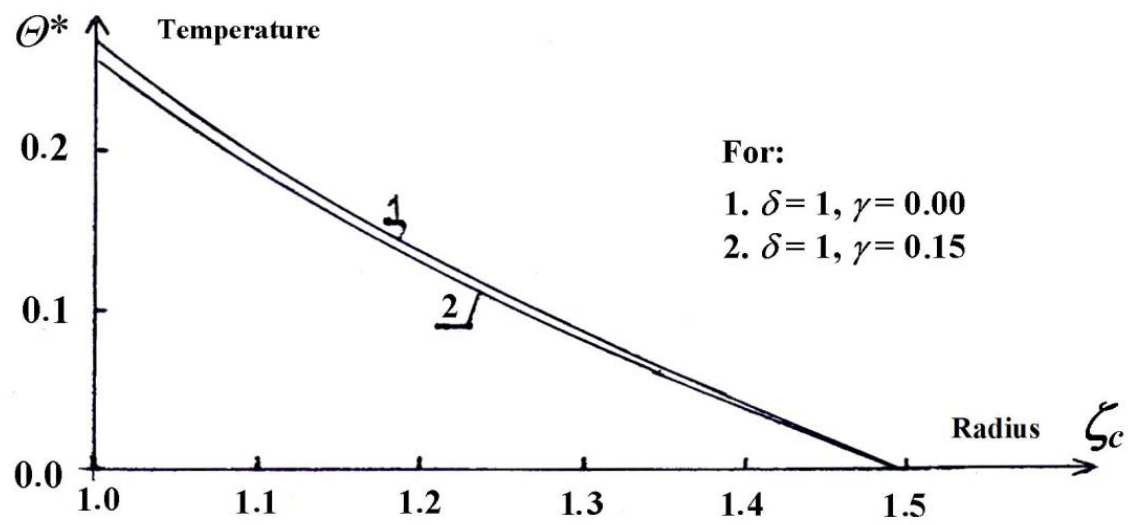

Fig.4. Curves of dimensionless temperature $\Theta *$ versus radius of the location of elastic-plastic zone $\zeta_{c}$. 


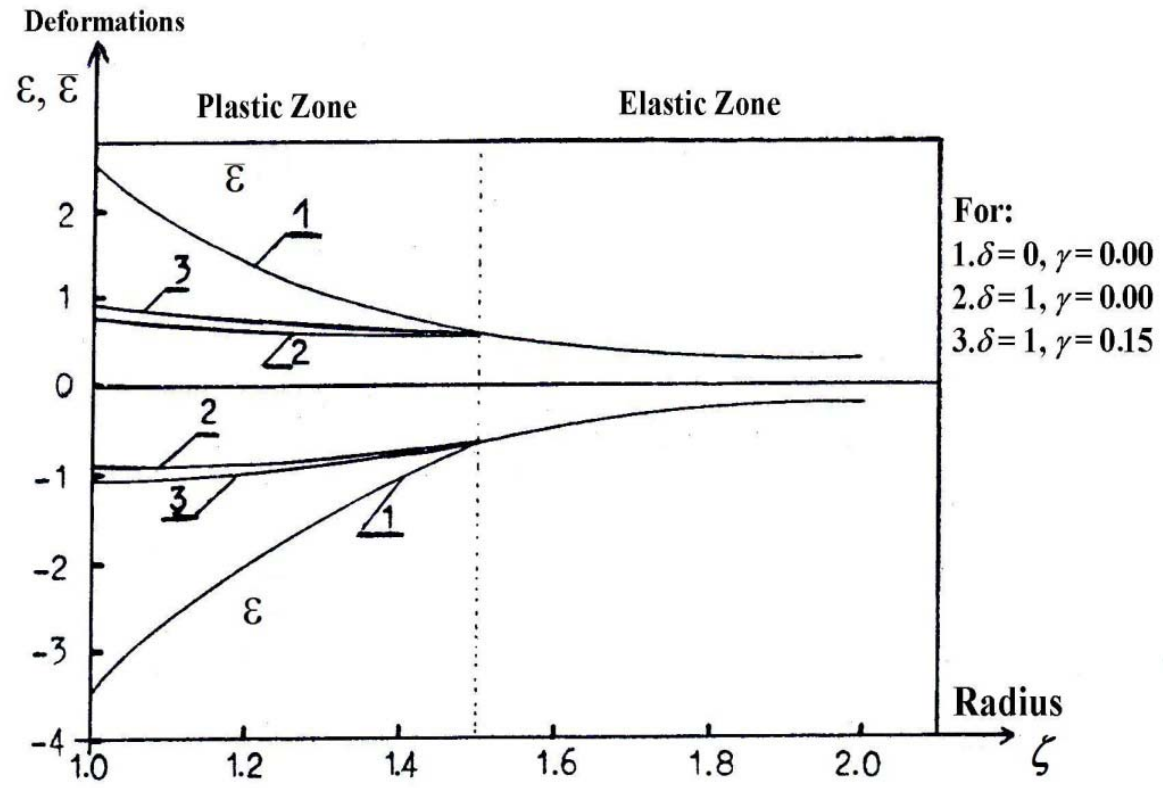

Fig.5. Distributions of dimensionless radial and circumferential total deformations $\varepsilon$ and $\bar{\varepsilon}$ versus current radius of thick-walled tube $\zeta$.

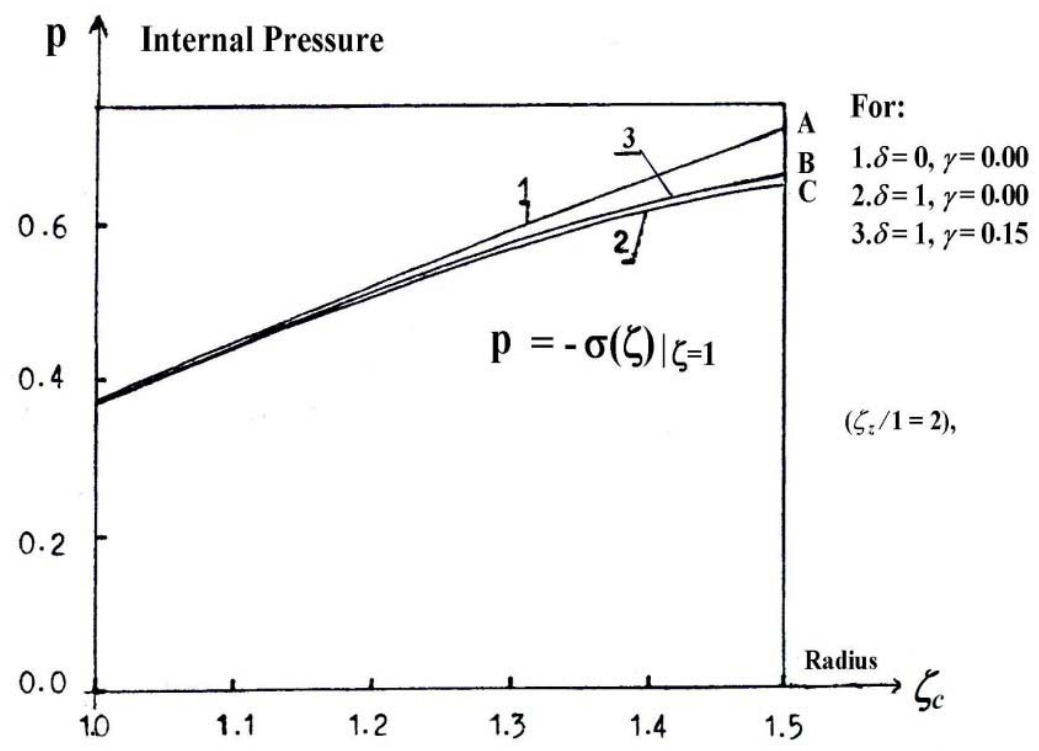

Fig.6. Curves of changes of dimensionless internal pressure $p$ versus of the location of elastic-plastic zone $\zeta_{c}$. 


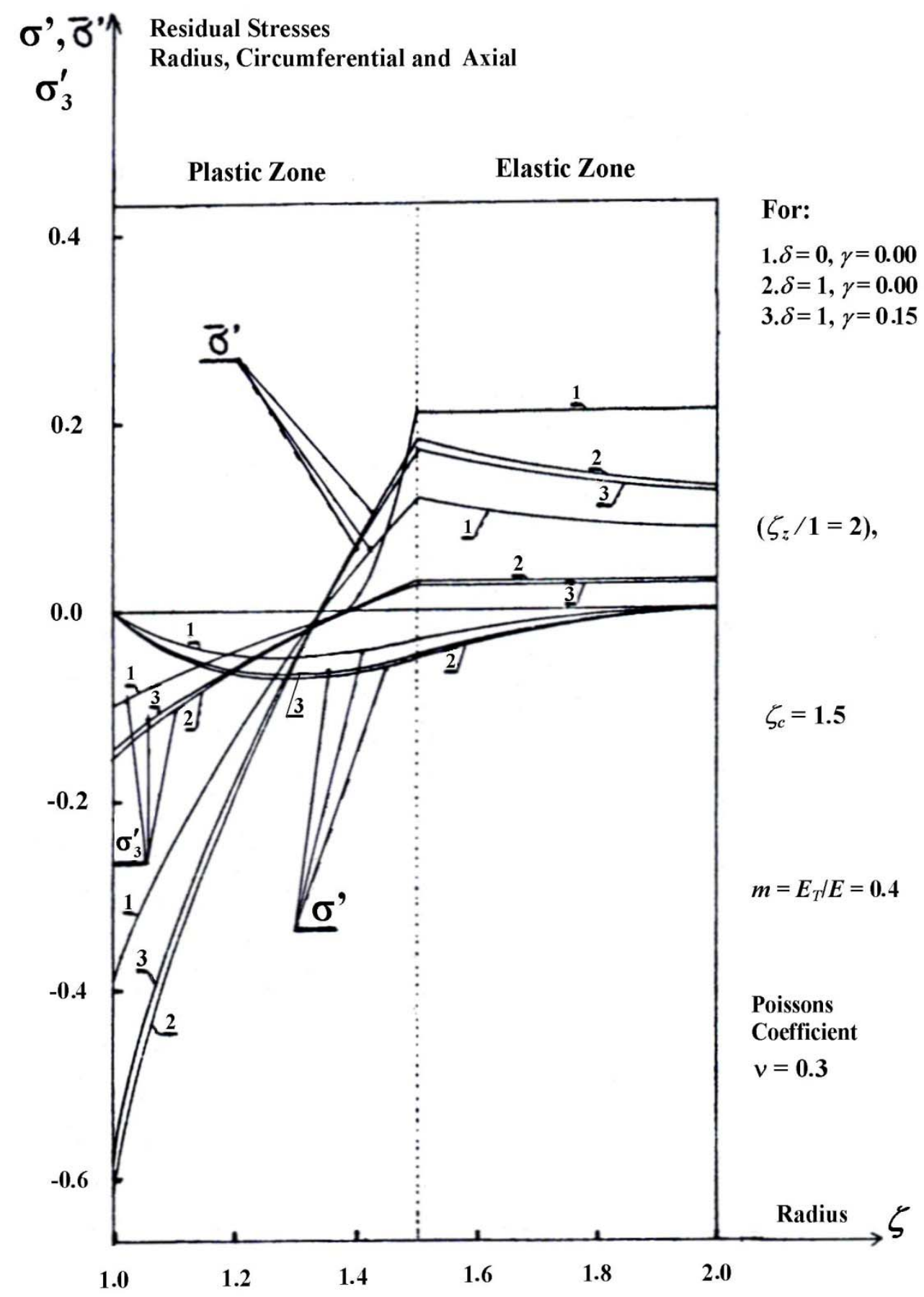

Fig.7. Curves of residual stresses $\sigma^{\prime}, \bar{\sigma}^{\prime}$ and $\sigma_{3}^{\prime}$ after the process of purely elastic unloading for the case of maximal value of internal pressure, suitable to radius $\left(\zeta_{c}=1.5\right)$, versus current radius of thick-walled tube $\zeta$.

In the analysis of the thick-walled tube one full cycle of internal pressure loading from zero to maximal and to zero value is made. We assumed that the maximal value of the radius of the elastic-plastic zone in this cycle is equal to half the thickness of the sphere wall and that the unloading process is purely elastic. 
As it is seen in Figs 3-5, on the border of the elastic-plastic zone (when $\zeta_{=} \zeta_{c}$ ) the stresses, strains (and adequate displacements) and also temperature are continous, respectively.

As we can see in Figs 3-7, the maximal values of calculated quantities: internal pressures, active and residual stresses (besides radial stresses), deformations and temperature are located on the inner surface of the thick-walled tube. It is possible that in these locations the first micro- and macro-crackings in the case of quasistatic (monotonic) or varying internal pressure load $p$ can occur (Bland, [1]; Koiter, [2]; Mendelson, [3]; Nied and Batterman, [4]; Śloderbach and Pajak, [7]; Hill, [13]).

In Tab.1 the calculated examples of pressures $p_{c r}$ from Eq.(3.2) and $p$ from Eq.(2.21), for three problems, namely: two thermomechanically coupled problems with and without taking into account the stored energy of plastic deformation (SEPD), respectively, and one thermomechanically uncoupled problem, are presented. The calculations were made for appropriately chosen parameters $\bar{z}, v, m$ and $\zeta_{c}$.

Table 1. Critical values of pressure $p_{c r}$ and of active internal pressure $p$.

\begin{tabular}{|c|c|c|c|}
\hline \multicolumn{4}{|c|}{$\bar{z}=2, v=0.3, m=E_{T} / E=0.4, \zeta_{c}=1.5$} \\
\hline$\delta$ & $\gamma$ & $p_{c r}$ & $p$ \\
\hline$\delta=0$ & $\gamma=0.00$ & 1.143 & 0.716 \\
\hline$\delta=1$ & $\gamma=0.00$ & 0.843 & 0.649 \\
\hline$\delta=1$ & $\gamma=0.15$ & 0.855 & 0.652 \\
\hline
\end{tabular}

Based on the results shown in Tab.1 it can be concluded, that for choosen: geometry $\bar{z}$ of the tube, linear hardening moduli $m$, Poisson's coefficient $v$ and radius of elestic-plastic zone $\zeta_{c}$ parameters, an unloading process is purely elastic (without plastic deformations) in all three cases under analysis, because $\left(p_{c r} \geq p\right)$, see expression (3.2).

The values of internal pressure $P$, see relation $(2.17)_{6}$, which corresponds - to points $\mathrm{A}, \mathrm{B}$ and $\mathrm{C}$ shown in Fig.6, are as follows

$$
\begin{aligned}
& P \cong 286.4 \mathrm{MPa} \text { for point } \mathrm{A} \text { and for }(\delta=0, \gamma=0.00), \\
& P \cong 259.4 \mathrm{MPa} \text { for point } \mathrm{B} \text { and for }(\delta=1, \gamma=0.00), \\
& P \cong 260.8 \mathrm{MPa} \text { for point } \mathrm{C} \text { and for }(\delta=1, \gamma=0.15) .
\end{aligned}
$$

These calculations were performed for $\sigma_{0}=400 \mathrm{MPa}$.

The values of absolute temperature $\Delta T$ increment corresponding to dimensionless temperatures $\Theta$ * measured on the internal surface of the thick-walled tube, see relation $(2.17)_{3}$, are the following

$$
\begin{aligned}
& \Delta T \cong 40.96 K \quad \text { for } \quad(\delta=1, \gamma=0.00), \\
& \Delta T \cong 39.46 K \quad \text { for } \quad(\delta=0, \gamma=0.15) .
\end{aligned}
$$

The calculations were made for the following parameters: $E=210 \mathrm{GPa}, \sigma_{0}=400 \mathrm{MPa}$ and $\alpha=$ $11 \cdot 10^{-6} 1 / K$.

\section{Remarks and conclusions}

1. It can be concluded that the thermomechanical effect (the effect of thermal expansion due to dissipation of the energy of plastic deformation) is represented by the parameter $\delta$. For the majority of metallic 
materials the value of the parameter $\delta$ is of the order of $10^{-3}$ and is very small (Nied and Batterman [4]). For the effective calculations we assumed that $\delta=1$ (Dillon [19]). This value of the parameter $\delta$ has a considerable influence on the distributions of: active stresses, deformations, acting internal pressure, temperatures and residual stresses after purely elastic unloading, see Figs 3-7. The maximal increase of temperature on the internal surface of the tube is about $40 \mathrm{~K}$.

2. Mechanical and thermomechanical loads and stresses induced by them can cause a lot of failures, defects, damages and destructions in installations working in many industrial branches and in power industry, see (Sokołowski, [5]; Śloderbach and Pajak, [6], [7]; Kocańda, [20], [21]; Macha, [22]; Neimitz et al., [23]; Łagoda [24]; Okrajni et al. [25], [26], [27]; Ziaja, [28]; Śloderbach and Pajak [29]).

3. A distribution of residual stresses, which arise in the thick-walled tube after a purely elastic unloading, was determined, see Fig.7. Analyzing the curves shown in Fig.7 we can see high values of residual stresses, which can reduce (shorten) the service life of those constructions during changing mechanical (Kocańda, [20], [21]; Macha, [22]) and thermomechanical loads (Bland, [1]; Neimitz et al., [23]; Lagoda [24]; Okrajni et al., [25], [26], [27]; Ziaja, [28]; Śloderbach and Pajak [29]).

4. An analysis of the influence of the stored energy of plastic deformation (SEPD) on the distribution of stresses, deformations, internal pressure, temperatures and residual stresses (Bever et al., [9]; Śloderbach et al., [10]; Śloderbach and Pająk, [11]; Raniecki, [14]; Śloderbach, [15]) was made. Maximal values of these calculated quantities (without radial residual stresses) occur on the internal surface of the thickwalled tube, see curves in Figs 3-7. The average value of $(\gamma=0.15)$ - parameter of thermomechanical coupling related to the stored energy of plastic deformation (SEPD) - was assumed in calculations. This physically means that about $15 \%$ of plastic work is stored in material in the plastic zone of the thickwalled tube.

5. In a future, the analysis of the thick-walled tube can be extended by adding a thermal load in the form of temperature gradient (Bland, [1]; Mendelson, [3]; Śloderbach and Pająk, [7]) and also an external pressure. It is also possible to take into account a new expression for the stored energy of plastic deformation (SEPD) derived in paper (Śloderbach and Rechul, [30]). The extended analysis may be performed for the cases when new plastic zones on the external surface and in the wall of the tube appear and when the whole wall becomes plastic. For higher temperatures it should be assumed that all the material constants of the thermo-elastic-plastic body model are dependent on temperature. These new ideas have to be solved with the help of numerical methods such as FEM, FDM, BEM or other methods.

\section{Nomenclature}

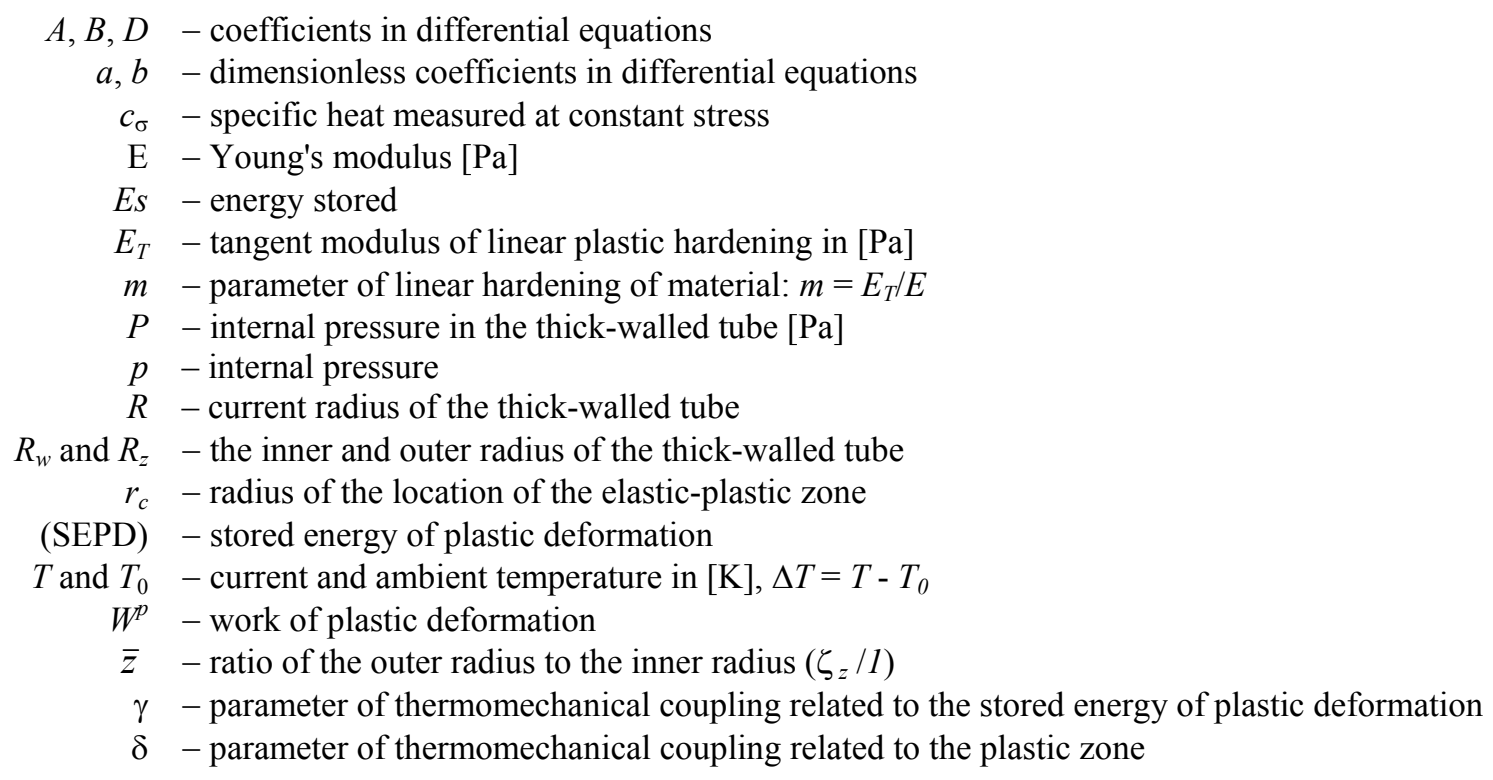


$\delta^{e}$ - parameter of thermomechanical coupling related to the elastic zone

$\varepsilon$ and $\bar{\varepsilon}-$ components of the strain tensor: radial and circumferential

$\varepsilon_{r}$ and $\varepsilon_{\theta} \quad-$ components of radial and circumferential deformation

$\Theta^{*} \quad$ - temperature, $\eta$ - time

$\zeta_{c}$ - radius of the location of the elastic-plastic zone

$\zeta$ and $\zeta_{z}$ - current radius and outer radius of the thick-walled tube

$\sigma, \bar{\sigma}$ and $\sigma_{3}$ - radial, circumferential and axial stresses

$\sigma_{e}$ and $\sigma_{0}-$ equivalent stress and initial plastic stress

$\sigma_{r}, \sigma_{\theta}$ and $\sigma_{z}-$ components of radial, circumferential and axial stresses

\section{References}

[1] Bland D.R. (1956): Elastoplastic thick-walled tubes of work-hardening material subject to internal and external pressures and to temperature gradient. - Journal of Mechanics and Physics of Solids, vol.4, pp.2009-229.

[2] Koiter W.T. (1953): On partially plastic thick-walled metal tubes. - Biezono Anniversary Volume in Applied Mechanics, N.V. De Technische Uitgeverij, H. Stam, Haarlem, pp.333-341.

[3] Mendelson A. (1968): Plasticity: Theory and Application. - New York: The Mc Millan Book Company, .

[4] Nied H.A. and Batterman S.C. (1971): On coupled thermoplasticity: an exact solution for a spherical domain.Israel Journal of Technology, vol.9, No.1-2, pp.37-46.

[5] Sokołowski M. (1960): Thermal stresses in spherical and cylindrical shells in the case when the material parametrs depend on temperature. - Engineerig Transactions, Warsaw, vol.8, No.4, pp.641-669.

[6] Śloderbach Z. and Pająk J. (2013): Analysis of thick-walled elastic-plastic sphere subjected to temperature gradient. - Journal of Thermal Stresses, vol.36, pp.1077-1095.

[7] Śloderbach Z. and Pająk J. (2010): Analysis of thick-walled elastic-plastic sphere subjected to internal pressure, part I. derivation of basic equations and expressions. - Optimization of the Structures of Manufacturing Processes, Opole University of Technology, No.276, pp.85-96.

[8] Życzkowski M. and Kordas Z. (1970): Fully plastically forming of the non-circular thick-walled cylinders in the failure state [in Polish]. - Engineering Transactions, IFTR-Reports, Warsaw, vol.21, No.4.

[9] Bever M.B., Holt D.L. and Titchener A.L. (1973): The stored energy of cold work. - Progress in Materials Science, London-Oxford, Pergamon Press, vol.17.

[10] Śloderbach Z., Pająk J. and Marciniak Z. (2008): Aproximate calculations of the stored energy of plastic deformation in tube bending processes. - Optimization of Production Processes, Opole University of Technology, No.238, pp.169-186.

[11] Śloderbach Z. and Pająk J. (2013): Stored energy of plastic deformations in tube bending processes. - International Journal of Applied Mechanics and Engineering, vol.18, No.1, pp.235-248.

[12] Sawczuk A., Janas M. and König J. (1972): Plactic Analysis of Constructions. - Wrocław: Ossolineum.

[13] Hill R. (1985): The Mathematical Theory of Plasticity. - London: Clarendon Press.

[14] Raniecki B. (1977): Problems of Applied Thermoplasticity [In Polish]. - DSc Thesis, IFTR-Reports, Warsaw, No.29/1977.

[15] Śloderbach Z. (1980): Bifurcations Criteria for Equilibrium States in Generalized Thermoplasticity [In Polish]. Doctor's thesis, IFTR-Reports, No 37/1980, Warsaw.

[16] Śloderbach Z. (2016): Closed system of coupling effects in generalized thermo-elastoplasticity. - International Journal of Applied Mechanics and Engineering, vol.1, No.2, pp.461-48.

[17] Boley B.A. and Weiner J.H. (1960): Theory of Thermal Stress. - New York: Wiley. 
[18] Nowacki W. (1962): Thermoelasticity. - Oxford: Pergamon Press.

[19] Dillon O.W. (1965): Coupled thermoplasticity when the material coupling parametr equals unity. - ASME Transactions, Series E87, pp.378-382.

[20] Kocańda S. (1985): Fatique Crack of Metals [in Polish]. - Warsaw: WNT.

[21] Kocańda S. and Kocańda A. (1998): Low Cycle Fatique Strength of Metals [in Polish]. - Warsaw: PWN.

[22] Macha E. (2001): A review of energy-based multiaxial fatigue failure criteria. - The Archive of Mechanical Engineering, vol. XLVIII, No.1, pp.71-101.

[23] Neimitz A., Dzioba I., Graba M. and Okrajni J. (2008): Assessment of strenght, durability and safety of work of the elements of constructions with deffects [in Polish]. - Kielce University of Technology.

[24] Łagoda T. (2007): Possibilities of application of the deformations energy density parameter in thermal stresses fatique [in Polish]. - Energetyka, Thematic Notebook XIV, ISSN 0013-7294, Katowice, pp.62-64.

[25] Okrajni J., Marek A., Plaza J. and Essler W. (2007): Thermomechanical fatique of the elements of installations of power plant [in Polish]. - Energetyka, Thematic Notebook XIV, ISSN 0013-7294, Katowice, pp.81-85.

[26] Okrajni J. (2008): Durability of the pressure elements of boilers according to standards [in Polish]. - Energetyka, Thematic Notebook XVIII, ISSN 0013-7294, Katowice, pp.93-100.

[27] Okrajni J., Junak G. and Marek A. (2008): Modelling of deformation process under thermo-mechanical fatique conditions. - International Journal of Fatique, vol.30, No.2, pp.324-329.

[28] Ziaja J. (1994): Heat low-temperature fatique of metals with hexagonal net of structure - failure criterion [in Polish]. - Scientific Works, Technical University of Wrocław, No.54, Series: Monograpfs, Wroclaw.

[29] Śloderbach Z. and Pająk J. (2017): Determination of the critical state during adiabatic process of thermoplastic deformation of metallic materials. - Journal of Thermal Stresses, vol.40, No.2, pp.255-265.

[30] Śloderbach Z. and Rechul Z. (2006): A thermodynamic approach to the stored energy concept. - Journal of Technical Physics, Warsaw, vol.XLVII, No.2, pp.83-102.

Received: February 26, 2018

Revised: March 21, 2018 